\title{
Absence of papilloedema in cerebral tumours
}

\author{
H. VAN CREVEL \\ From the Department of Neurology, Erasmus University \\ Academisch Ziekenhuis Dijkzigt, Rotterdam, Netherlands
}

SYNOPSIS Fluorescein fundus angiography in 10 patients with a cerebral tumour of considerable size but without ophthalmoscopic papilloedema does not support the hypothesis that such patients have in fact minimal papilloedema. Absence of papilloedema in these cases usually indicates absence of persistently high CSF pressure.

In patients with cerebral tumours, papilloedema is an important sign; but it is absent in $40 \%$ of cases examined with the ophthalmoscope (Petrohelos and Henderson 1951; Brégeat, 1956; Tönnis, 1959; Huber 1971). This could be due to normal or only slightly raised CSF pressure in these cases, but also to shortcomings of ophthalmoscopy.

Fluorescein fundus angiography has not only proved a sensitive method for the differentiation of pseudo-papilloedema from early papilloedema in cerebral tumours (Miller et al., 1965; Oosterhuis and Boen-Tan, 1969), but may even detect

(Accepted 9 May 1975.) 'sub-ophthalmoscopic' oedema of the optic disc in retrobulbar neuritis (Rosen and Ashworth, 1968; Hayreh, 1969).

It seems possible, then, that cases of cerebral tumour with 'normal' optic discs have, in fact, some papilloedema on fluorescein fundus angiography. The present investigation was undertaken to explore that possibility.

\section{METHODS}

Ten patients were studied (Table). All had primary or metastatic cerebral tumours, and on admission none had ophthalmoscopic papilloedema as judged by the neurologist. The localization of the tumours

TABLE

PATIENTS WITH CEREBRAL TUMOURS WITHOUT PAPILLOEDEMA

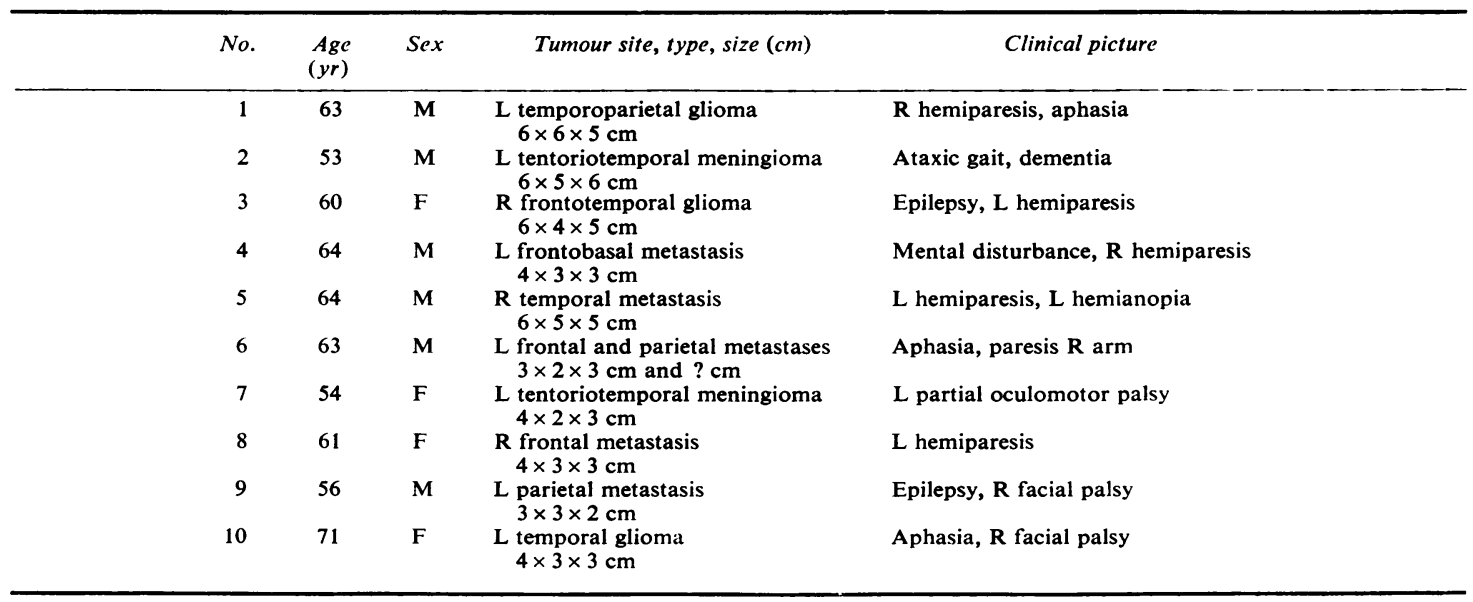


and the main clinical features are summarized in the Table. The diagnosis was verified histologically in six patients; in cases 5,6 , and 9, the clinical evidence for metastases was convincing, and the patients were treated with dexamethasone and radiotherapy; in case 7, operation is being postponed, but angiography showed the typical 'flush' compatible with a meningioma. Brain scans were made in all cases. Further ancillary investigations were carried out as indicated in each patient: carotid and/or vertebral angiography, cisternal pneumoencephalography, or ventriculography.

Special attention was paid to the size of the tumours. This was determined in three dimensions (sagittal, vertical, and coronal), using the combined diagnostic studies, especially the angiography subtraction pictures and the brain scans.

CSF pressure was measured in eight patients where ventricular puncture (case 2) or cisternal puncture (the other patients except cases 3 and 10) had to be done. Cisternal fluid pressure was measured in the half-sitting position used routinely for pneumoencephalography in our department, with the shoulder as reference point. In a large number of cases this technique has proved to produce values roughly equal to those of lumbar puncture in the horizontal position. Ventricular pressure was recorded continuously for eight hours in case 2 with a Sanborn transducer.

Fluorescein fundus angiography (preceded by ordinary ophthalmoscopy and photography) was performed and interpreted by Dr K. J. Zahn at the Eye Hospital, particular attention being paid to the features of papilloedema : capillary dilatation, microaneurysms, and leakage at the optic discs. The procedure introduced an element of selection, because patients have to be in fairly good condition for this examination.

\section{RESULTS}

FLUORESCEIN FUNDUS ANGIOGRAPHY The fluorescein pictures showed no signs of papilloedema at all in nine of the 10 patients.

In case 6 , some dilated capillaries and a few microaneurysms were seen in and around the optic disc, with discrete leakage of fluorescein at and around the disc, persisting during the late phase. The picture was suspicious of incipient papilloedema. However, when this examination was done, three days after admission, the same conclusion was made by the ophthalmologist, Dr K. J. Zahn, from ophthalmoscopy and fundus photography alone.
In statistical terms, this result means that at most $28 \%$ of patients with a cerebral tumour but no ophthalmoscopic papilloedema might have a 'positive' fluorescein fundus angiogram $(P<0.05)$. This holds when this series is considered as none 'positive' out of nine cases.

SIZE OF TUMOURS All tumours could be measured in three dimensions (sagittal, vertical, and coronal), except the second metastasis in case 6 . The average size was considerable: $4.6 \times 3.6 \times$ $3.8 \mathrm{~cm}$. It was striking that the size of the tumour often bore little relation to the amount of shift of cerebral structures. Thus, the large tumour in case 1 caused no shift of the midline vessels on carotid angiography, whereas smaller tumours sometimes produced more than $2 \mathrm{~cm}$ midline shift.

CSF PRESSURE This was normal (less than $18 \mathrm{~cm}$ water) in three and slightly raised (more than $18 \mathrm{~cm}$ water) in four cases, with values ranging from 8 to $25 \mathrm{~cm}$ water. In case 4 the pressure was high: $50 \mathrm{~cm}$ water. Continuous ventricular fluid pressure recording was performed in case 2 . This 53 year old man with a large tentorial meningioma extending into both the middle and the posterior fossa, was monitored for eight hours; the pressure fluctuated between 15 and $20 \mathrm{~cm}$ water.

\section{DISCUSSION}

The results make it unlikely that the majority of cerebral tumour patients with normal discs on ophthalmoscopy have 'sub-ophthalmoscopic' papilloedema when examined with fluorescein fundus angiography. Indeed, the one patient with minimal signs of papilloedema both on fluorescein and on ophthalmoscopic examination-at that time-tends to bolster confidence in the ophthalmoscope, if used repeatedly.

It is known that the correlation between papilloedema and the size of the cerebral tumour producing it is low (Brégeat, 1956) or even absent (Tönnis and Krenkel, 1957). The present series confirms that papilloedema may be lacking with tumours of considerable size, both benign and malignant.

However, there is a high (though not absolute) correlation between papilloedema and CSF pres- 
sure in cerebral tumours, known from the literature on lumbar puncture (Lubic and Marotta, 1954; Korein et al., 1959; van der Lugt and Molin, 1968), from continuous recording of ventricular fluid pressure in cerebral tumours (Lundberg, 1960), and confirmed for cisternal fluid pressure in experimental space-occupying lesions (Hayreh, 1968). Accordingly, in the present series the CSF pressure was normal or only slightly raised in seven of the eight cases where it was measured. Only case 4 had a high pressure and he developed papilloedema the week after it was measured. In this respect, the time factor should always be borne in mind. Other factors necessary for the development of papilloedema in the presence of high CSF pressure are patency of the optic nerve sheath, nonatrophic optic discs, and normal ocular pressure (Hayreh, 1968; Walsh and Hoyt, 1969).

In conclusion it can be said, with the above qualifications, that absence of papilloedema in cerebral tumours is usually not due to shortcomings of the ophthalmoscope, but to absence of persistently high CSF pressure. Conversely, the presence of papilloedema remains a useful sign of high CSF pressure (Miller and Adams, 1972). This is the more important since continuous CSF pressure recording has shown that other clinical signs of 'raised intracranial pressure' are very unreliable (Lundberg, 1960; Jennett and Johnston, 1972).

I am grateful to Dr K. J. Zahn for performing and interpreting the fluorescein studies, to Mr R. van Strik for statistical advice, to Dr C. J. J. Avezaat for recording the ventricular fluid pressure in case 2 , and to my colleagues for referring their patients.

\section{REFERENCES}

Brégeat, P. (1956). L'Oedème Papillaire, pp. 544-545. Masson: Paris.
Hayreh, S. S. (1968). Pathogenesis of oedema of the optic disc. Documenta Ophthalmologica, 24, 289-411.

Hayreh, S. S. (1969). Blood supply of the optic nerve head and its role in optic atrophy, glaucoma, and oedema of the optic disc. British Journal of Ophthalmology, 53, 721-748.

Huber, A. (1971). Eye Symptoms in Brain Tumors, p. 91, 2nd edn. Mosby: St. Louis.

Jennett, B., and Johnston, I. H. (1972). The uses of intracranial pressure monitoring in clinical management. In Intracranial Pressure, pp. 353-356. Edited by M. Brock and $\mathrm{H}$. Dietz. Springer: Berlin.

Korein, J., Cravioto, H., and Leicach, M. (1959). Reevaluation of lumbar puncture. A study of 129 patients with papilledema or intracranial hypertension. Neurology (Minneap.), 9, 290-297.

Lubic, L. G., and Marotta, J. T. (1954). Brain tumor and lumbar puncture. Archives of Neurology and Psychiatry, 72, 568-572.

Lugt, P. J. M. van der, and Molin, C. E. (1968). Factors influencing cerebral pulsations in ECHO encephalography. Acta Neurochirurgica, 18, 246-255.

Lundberg, N. (1960). Continuous recording and control of ventricular fluid pressure in neurosurgical practice. Acta Psychiatrica et Neurologica Scandinavica, 36, suppl. 149.

Miller, D., and Adams, H. (1972). Physiopathology and management of increased intracranial pressure. In Scientific Foundations of Neurology, pp. 308-324. Edited by $M$. Critchley, J. L. O'Leary, and B. Jennett. Heinemann: London.

Miller, S. J. H., Sanders, M. D., ffytche, T. J. (1965). Fluorescein fundus photography in the detection of early papilloedema and its differentiation from pseudo-papilloedema. Lancet, 2, 651-654.

Oosterhuis, J. A., and Boen-Tan, T. N. (1969). Fluorescein angiography in papilloedema and pseudo-papilloedema. Ophthalmologica, 159, 96-110.

Petrohelos, M. A., and Henderson, J. W. (1951). The ocular findings of intracranial tumor, a study of 358 cases. American Journal of Ophthalmology, 34, 1387-1394.

Rosen, E. S., and Ashworth, B. (1968). Serial fluorescein photography in acute retrobulbar neuritis. Journal of Neurology, Neurosurgery, and Psychiatry, 31, 253-258.

Tönnis, W. (1959). Die sog. 'klassischen' Symptome der intrakraniellen Drucksteigerung, and Stauungspapille. In Handbuch der Neurochirurgie, pp. 322 and 326. Edited by H. Olivecrona and W. Tönnis. Bd I/1. Springer: Berlin.

Tönnis, W., and Krenkel, W. (1957). Grosshirngeschwülste ohne Stauungspapille. Acta Neurochirurgica, 5, 458-487.

Walsh, F. B., and Hoyt, W. F. (1969). Clinical Neuroophthalmology, pp. 571-573, 3rd edn. Williams and Wilkins: Baltimore. 